\title{
Climate information needs of Gascoyne-Murchison pastoralists: a representative study of the Western Australian grazing industry
}

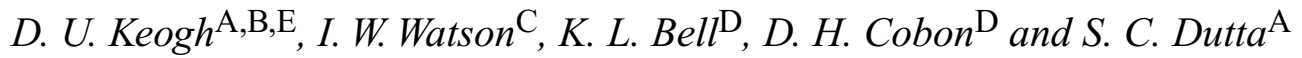 \\ ${ }^{\text {A } Q u e e n s l a n d ~ D e p a r t m e n t ~ o f ~ N a t u r a l ~ R e s o u r c e s ~ a n d ~ M i n e s, ~} 203$ Tor Street, Toowoomba, Qld 4350, Australia. \\ ${ }^{B}$ Current address: International Laboratory for Air Quality and Health, Queensland University of Technology, \\ GPO Box 2434, Brisbane, Qld 4000, Australia. \\ ${ }^{\mathrm{C}}$ Department of Agriculture Western Australia and Centre for Management of Arid Environments, \\ PO Box 483, Northam, WA 6401, Australia. \\ ${ }^{\mathrm{D}}$ Climate and Systems Technologies, Queensland Department of Primary Industries and Fisheries, \\ 203 Tor Street, Toowoomba, Qld 4350, Australia. \\ ${ }^{\mathrm{E}}$ Corresponding author. Email: dianekeogh@westnet.com.au
}

Abstract. The Gascoyne-Murchison region of Western Australia experiences an arid to semi-arid climate with a highly variable temporal and spatial rainfall distribution. The region has around 39.2 million hectares available for pastoral lease and supports predominantly cattle and sheep grazing leases. In recent years a number of climate forecasting systems have been available offering rainfall probabilities with different lead times and forecast periods; however, the extent to which these systems are capable of fulfilling the requirements of the local pastoralists is still ambiguous. Issues can range from ensuring forecasts are issued with sufficient lead time to enable key planning or decisions to be revoked or altered, to ensuring forecast language is simple and clear, to negate possible misunderstandings in interpretation. A climate research project sought to provide an objective method to determine which available forecasting systems had the greatest forecasting skill at times of the year relevant to local property management. To aid this climate research project, the study reported here was undertaken with an overall objective of exploring local pastoralists' climate information needs. We also explored how well they understand common climate forecast terms such as 'mean', 'median' and 'probability', and how they interpret and apply forecast information to decisions. A stratified, proportional random sampling was used for the purpose of deriving the representative sample based on rainfall-enterprise combinations.

In order to provide more time for decision-making than existing operational forecasts that are issued with zero lead time, pastoralists requested that forecasts be issued for May-July and January-March with lead times counting down from 4 to 0 months. We found forecasts of between 20 and $50 \mathrm{~mm}$ break-of-season or follow-up rainfall were likely to influence decisions. Eighty percent of pastoralists demonstrated in a test question that they had a poor technical understanding of how to interpret the standard wording of a probabilistic median rainfall forecast. This is worthy of further research to investigate whether inappropriate management decisions are being made because the forecasts are being misunderstood.

We found more than half the respondents regularly access and use weather and climate forecasts or outlook information from a range of sources and almost three-quarters considered climate information or tools useful, with preferred methods for accessing this information by email, faxback service, internet and the Department of Agriculture Western Australia's Pastoral Memo. Despite differences in enterprise types and rainfall seasonality across the region we found seasonal climate forecasting needs were relatively consistent. It became clear that providing basic training and working with pastoralists to help them understand regional climatic drivers, climate terminology and jargon, and the best ways to apply the forecasts to enhance decision-making are important to improve their use of information. Consideration could also be given to engaging a range of producers to write the climate forecasts themselves in the language they use and understand, in consultation with the scientists who prepare the forecasts.

Additional keywords: graziers, needs analysis, ranchers, seasonal climate forecasting systems. 


\section{Introduction}

\section{Challenges associated with climate forecast information}

Dissemination and use of forecasts are considerably more complex than the majority of researchers assume (Broad et al. 2002; Feldman 1989; Glantz 1996). For example, interpretation of forecasts by users and linguistic composition need to be studied from the point of view of the potential end user (Childs et al. 1991).

The way a forecast is worded and presented can affect judgments and decision making (Coventry and Dalgleish 2000) and the ability of users to interpret it (Coventry and Dalgleish 2000; W. Coventry, L. Dalgleish, R. McCrea, unpublished data). Producers can find a statement referring to probability difficult to understand and altering the forecast wording, in the case of non-phase systems, from, for example, 30 and $70 \%$ probability to 'in 3 in 10 ' or 'in 7 in 10 years', respectively, can greatly enhance end-users' ability to correctly interpret the forecast statement (W. Coventry, L. Dalgleish, R. McCrea, unpublished data), as can employing wording for historical relative frequency forecasts (applicable to Southern Oscillation Index phase system forecasts; i.e. Stone et al. 1996) such as 'of the 23 years with a similar SOI phase, $40 \%$ of them had above median rainfall' (Coventry and Dalgleish 2000).

Conversely, the wording of a forecast may lead to confusion in interpretation. Unintended interpretation of terms can occur in the communication process and become a source of confusion (Ayton 1988; Murphy and Brown 1983), particularly with respect to probabilistic information. The concept of probability can be difficult to communicate; and users of probabilistic information need to understand that an element of chance is involved (Coventry and Dalgleish 2000). A probabilistic forecast seeks to communicate not only the probability of an event occurring, but also the probability that an event may not occur. Users may need assistance with interpreting probabilistic forecasts. They may need more information and education about how to use predictions (Jochec et al. 2001; Klopper 1999; Sonka et al. 1992).

\section{What climate information is useful to producers?}

Producers need to be consulted concerning what information they need and expect, and the best way to present it to them (Klopper 1999; Podestá et al. 2002). These needs should guide design of training to aid adoption (Podestá et al. 2002). Improving predictive accuracy alone may not increase usage substantially (Changnon 1992) and the aspect of forecast quality that is most useful may depend on the type of decision being made (Hartmann et al. 2002).

But what are the current levels of use of forecasts by producers and how are they using them? Can users understand the language of the scientist? Are producers correctly interpreting the forecast information they are receiving and, if not, are there consequences associated with misinterpretation of forecasts?

\section{Characteristics of rainfall forecasts}

Rainfall forecasts have a number of characteristics that can influence uptake. These can range from the period being forecast, to lead time, probability of occurrence, amount of rainfall forecast and its predicted timing (for example, whether break-of-season or follow-up seasonal rain). Another characteristic is the level of complexity of language used in the forecast and whether it can be easily interpreted by non-scientific users.

A balance may need to be struck between timeliness of a forecast and its skill. For example, a less skilful forecast issued with sufficient lead time may be more valuable than a highly skilful forecast that arrives at a time when a producer's decision cannot be revoked (Ingram et al. 2002). Producers' information requirements need to be carefully ascertained and incorporated in design and dissemination of forecasts and related training opportunities, and in developing forecast skill testing activities to ensure any forecast outputs match the timing and information needs of the users.

\section{Managing grazing properties in the Gascoyne-Murchison region}

Agricultural managers in this region of Western Australia (Fig. 1) manage extensive properties in an arid to semi-arid rangeland that experiences rainfall variability that is both higher than the global average for regions with the same mean annual rainfall (Nicholls et al. 1997) and higher than most other agricultural regions in Australia (Lee and Gaffney 1986).

Probabilistic rainfall forecasts that relate to monthly, seasonal or annual timeframes, hereafter termed seasonal climate forecasts, may have the potential to aid risk management in the region, as may the decadal cycle influences (10-year timeframe) on a seasonal forecast. For

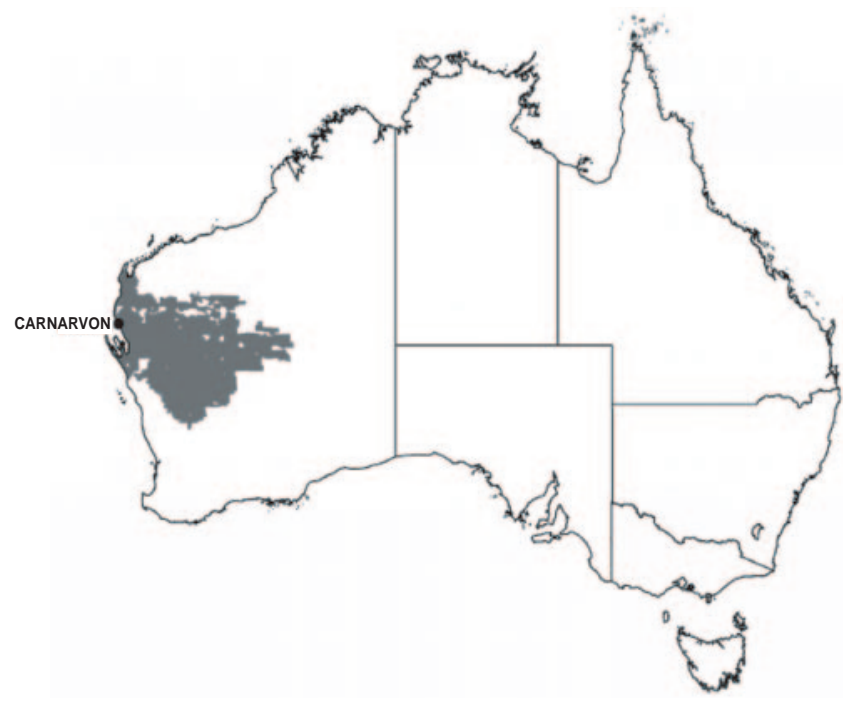

Figure 1. Survey region in the Gascoyne-Murchison region of Western Australia. 
example, a seasonal climate forecast known to have good skill may influence a decision at shearing to increase or decrease on-property stocking rates. Managing this type of risk has important social, economic and natural resource management implications, particularly given the hardship and degradation that has occurred in Australia's rangelands during extended periods of low rainfall (McKeon et al. 2004).

Low wool prices in the region in the early 1990s and low rainfall in 1992 and 1993 led to the development of the Gascoyne-Murchison Strategy (GMS), which addressed economic development, structural adjustment and natural resource management needs in the region (Anon. 1997; Lewis 2001). One of its initiatives was the establishment of a research project in collaboration with the Department of Agriculture Western Australia, and the Queensland Departments of Primary Industries and Fisheries and Natural Resources and Mines to review the performance of a number of seasonal forecasting systems to identify those with the highest skill that meet the climate information needs of GMS pastoralists. This research project was important to GMS producers not only because the skill of the forecasting systems would be tested, but because it was being undertaken specifically for the rangelands of their region, towards the west coast of Australia where, traditionally, seasonal climate forecasts have been crude or even anecdotal, and the estimate of skill simply an assessment made by managers based on their own experiences.

\section{Objectives of our study}

To help the research project develop appropriate skill testing regimes for the forecasting systems being evaluated that related directly to the climate information needs of local pastoralists, a needs analysis and stakeholder survey was undertaken. This paper presents the results of a mailed questionnaire.

The objectives of our study were to explore (i) general enterprise characteristics and practices of GMS pastoralists; (ii) timing of key decisions and management activities; (iii) amounts of rain in different seasons and probability levels of forecasts likely to influence producers; (iv) currently accessed sources of weather and climate information; (v) levels of understanding and application of this information to decisions; and (vi) preferred methods for accessing climate information.

Keogh et al. $(2003 a, 2003 b)$ provide a more comprehensive summary of the mail survey results and include an electronic copy of the questionnaire used in the study.

\section{Gascoyne-Murchison Strategy region}

The majority of the region is pastoral leasehold used for extensive livestock grazing and at the time of survey had about 240 pastoral leases, covering an area of approximately 39.2 million ha (Fig. 1) with an average leasehold of
163341 ha (Department of Agriculture Western Australia, unpublished statistics 2002).

Livestock carrying capacities in the region are low and ranged from 5-20 hectares per dry sheep equivalent (ha/dse), or 35-140 hectares per Large Stock Unit (Payne et al. 1987; Pringle et al. 1994; Van Vreeswyk and Godden 1998; Wilcox and McKinnon 1972). Most properties ran beef cattle or Merino sheep or a mix of both. Sheep tended to dominate in the south-west and cattle in the north-east, where lease areas were larger. Feral goat sales now provide a significant part of station income (Pastoral Industry Economic Monitoring Requirements Pastoral Industry Working Group 2003).

The region experiences an arid to semi-arid climate with average annual rainfall around $200-250 \mathrm{~mm}$, except along the south-western margins where it ranges from about 270-290 mm (Bureau of Meteorology 1998) and annual variability ranges from high to extreme. For austral warm season rainfall (e.g., January-March) almost the entire region is considered to have extreme variability (variability maps, Bureau of Meteorology 2004). This variability is one of a number of risks managers of extensive grazing properties in the GMS region need to plan and manage for.

Most rainfall in the region occurs in 2 seasons, during May-July and January-March, with variable amounts in April; rainfall during August-December is typically low and cyclones occur most frequently in February and March (Bureau of Meteorology 1998).

The proportion of total rainfall received in the May-October period, when compared with the annual total, varies from around $30 \%$ in the far northeast of the region to more than $80 \%$ in the extreme south-west (Bureau of Meteorology 1998). In terms of annual management decisions the reliability of austral cool season rainfall allows some degree of consistency, while decisions based on austral warm season rainfall tend to be more opportunistic.

\section{Research project that tested climate forecasting systems for the region}

The results of the mail survey helped the research project develop 'what-if' skill test scenarios for 8 potential seasonal climate forecasting systems. Two of the potential systems were operational - the Southern Oscillation Index phase system (SOI) (Stone et al. 1996) and the SSTAnom Australian Bureau of Meteorology operation system (Australian Bureau of Meteorology, see Drosdowsky and Chambers 2001) and 6 were experimental. The 6 experimental systems included (i) CSIRO: global SST regression system (McIntosh et al. 2002, in press); (ii) Latitude of the sub-tropical ridge (LSTR) (A. A. J. Williams, P. de Voil, R. C. Stone, unpublished data); (iii) Pacific Decadal Oscillation + Niño, 3.4 (Hamlet and Lettenmaier 1999); (iv) Seasonal Pacific Ocean Temperature Analysis-1 (SPOTA-1) (Day et al. 2000); (v) Tidal model (Treloar 2002) and (vi) SST9: Commonwealth Bureau of 
Meteorology 9 phase SST (Drosdowsky 2002). The evaluation by the research project found insufficient skill for the austral cool season and some skill for the austral warm season. Full details of their skill testing (Kruskal Wallis; Kolmogorov-Smirnov; Linear Error in Probability Space) results may be found in project milestone reports by Cobon et al. (2004) and Stone et al. (2004).

\section{Materials and methods}

Sampling design

The Department of Agriculture, Western Australia provided a list of the population of 240 pastoral leases that included enterprise type, station size and the name and address of lessees or managers. Sixty-six leases were excluded from the population as they were either part of an enterprise holding more than one lease or related to an enterprise not considered at the time of the survey to be operating as a commercial grazing enterprise, leaving an in-scope population of 174 station enterprises operating commercial grazing enterprises (Keogh et al. $2003 a, 2003 b)$.

To achieve representative sampling, the stratified random sampling and cumulative square root of the frequency method techniques suggested by Scheaffer et al. (1990) were used to draw a representative sample of the pastoral enterprises (Table 1).

\section{Measurable attribute selected for population stratification}

In order to design a representative sample, data is needed on a measurable attribute(s) of a population that is relevant for the purpose of the study. There can be many ways to categorise decision-makers which can relate to attributes associated with styles of farming or individual grazing management behaviour (Burnside 1994; Vanclay 2004) that may influence, for example, landscape characteristic or stocking rate level judgments.

In our study, the attribute we selected was percent of annual rainfall during the austral cool season (e.g., May-October) and a minimum optimum sample size was calculated at a confidence limit of $95 \%$. This sample size represents the minimum number of leases required to represent the population.

This attribute was selected on the basis that pastoral industries are dependent upon pasture growth, which in turn is dependent upon amount, timing and distribution of rainfall. The population was divided into 3 rainfall categories based on the percent of annual rainfall received during May-October at each property's Bureau of Meteorology rainfall station (mostly homesteads). Effectively, this split the region into cool season dominated; warm season dominated and cool/warm season dominated rainfall areas (see below). The analysis used the SILO Patched Point Dataset (http://www.nrm.qld.gov.au/silo/ppd/, verified 25 November 2005), which combined the Bureau of Meteorology measurements for each station with infilling of any gaps (Jeffrey et al. 2001) to give a continuous record. May-October has been used by the Bureau of Meteorology to segment the region's inter-annual rainfall pattern (Bureau of Meteorology 1998).

\section{Stratified, proportional random sampling using 2 strata}

Strata 1: rainfall categories. This sampling design was employed and the first stratification involved delineation of 3 rainfall categories (as detailed above). The cumulative square root of the frequency method was applied to the frequency data on broad categories of the related rainfall during May-October and frequency analysis used to divide the leases into 3 categories. The percent of mean annual rainfall falling in the austral cool season (i.e. May-October) was used as the basis for stratifying on rainfall seasonality. The 3 rainfall categories delineated after applying the cumulative square root frequency technique were $<45 \%$ (Category 1, austral warm season), $45-55 \%$ (Category 2, austral $\mathrm{cool} /$ warm season) and $>55 \%$ (Category 3 , austral cool season).

Forty-four percent of enterprises in the sample area were classified as Category 1,25\% Category 2 and 31\% Category 3. Average lease area decreased from 283933 ha for Category 1 to 161970 ha for Category 2 and 145373 for Category 3 . This inverse relationship between average lease size and proportion of cool season rainfall may reflect the importance and influence of cool season rainfall reliability, with higher carrying capacity and smaller lease areas very dependent on more reliable rainfall in the austral cool season.

Strata 2: enterprise type for proportional randomisation. As we did not have access to measurable information on other lease attributes (apart from rainfall data used in the first stratification) we used enterprise numbers for proportional randomisation. The second stratification was based on enterprise type and used to proportionally sample the population. Enterprises were stratified into 3 categories: cattle, sheep or mixed (both cattle and sheep). Of the 174 enterprises, $24 \%$ ran cattle, $49 \%$ sheep and $27 \%$ mixed (both cattle and sheep) (Table 1). Most enterprises in rainfall Category 1 ran cattle; mixed in Category 2; and an almost even spread between sheep and mixed in Category 3.

\section{Minimum optimum sample size}

Considering the variance in the percent of annual rainfall received during May-October, the proportional optimal sampling size was determined using the following equation (Scheaffer et al. 1990):

$$
n=\frac{\sum_{i=1}^{L} N_{i}^{2} \sigma_{i}^{2} / w_{i}}{N^{2} D+\sum_{i=1}^{L} N_{i} \sigma_{i}^{2}},
$$

where, $n$ is minimum optimum sample size for the population, $N_{i}$ is the total number in enterprise $i, \sigma_{i}$ is the sample standard deviation of the rainfall category $i$ for any enterprise chosen, $w_{i}$ is the percent of the population in enterprise $i, D=B^{2} / 4, B$ is the bound on the error of

Table 1. Stratified, proportional random sampling design of the Gascoyne-Murchison Strategy region grazing industry according to rainfall and enterprise categories

$\mathrm{X} 1$, total number in the population; $\mathrm{X} 2$, number required for the representative sample; X3, number received from survey

\begin{tabular}{|c|c|c|c|c|c|c|c|c|c|c|c|c|}
\hline \multirow[t]{4}{*}{ Enterprise } & \multicolumn{9}{|c|}{ May-October rainfall as a percent of total annual rainfall } & \multicolumn{3}{|c|}{ Total } \\
\hline & \multirow{2}{*}{\multicolumn{3}{|c|}{$\begin{array}{c}\text { Category } 1<45 \% \\
\text { Austral warm season }\end{array}$}} & \multirow{2}{*}{\multicolumn{3}{|c|}{$\begin{array}{c}\text { Category } 245-55 \% \\
\text { Austral cool-warm season }\end{array}$}} & \multirow{2}{*}{\multicolumn{3}{|c|}{$\begin{array}{l}\text { Category } 3>55 \% \\
\text { Austral cool season }\end{array}$}} & \multirow[b]{3}{*}{$\mathrm{X} 1$} & \multirow[b]{3}{*}{$\mathrm{X} 2$} & \multirow[b]{3}{*}{$\mathrm{X} 3$} \\
\hline & & & & & & & & & & & & \\
\hline & $\mathrm{X} 1$ & $\mathrm{X} 2$ & $\mathrm{X} 3$ & $\mathrm{X} 1$ & $\mathrm{X} 2$ & $\mathrm{X} 3$ & $\mathrm{X} 1$ & $\mathrm{X} 2$ & $\mathrm{X} 3$ & & & \\
\hline Mixed & 17 & 5 & 5 & 16 & 5 & 11 & 15 & 5 & 9 & 48 & 15 & 25 \\
\hline Sheep & 6 & 2 & 3 & 20 & 6 & 6 & 59 & 15 & 15 & 85 & 23 & 24 \\
\hline Subtotal & 52 & 16 & 20 & 44 & 13 & 20 & 78 & 23 & 27 & 174 & 52 & 67 \\
\hline
\end{tabular}


estimation at a given confidence interval ( $95 \%$ assumed), thus, $B$ is the product of variance and $z_{(1-\alpha / 2)}$.

Therefore, $B$ is given by:

$$
B=z_{(1-\alpha / 2)} \times \sqrt{\frac{1}{N^{2}} \sum_{i=1}^{L} N_{i}^{2}\left(\frac{N_{i}-n_{i}}{N_{i}}\right)\left(\frac{s_{i}^{2}}{n_{i}}\right)},
$$

where, $n_{i}$ is the sample chosen in enterprise $i, s_{i}$ is the sample standard deviation of May-October rainfall for enterprise $i, N$ is the total population size.

The minimum optimum sample size to represent the Gascoyne-Murchison Strategy region was 52 as per equation 1 (we rounded the sample size to 55). Leases were proportionally distributed amongst the 9 sampling categories. To divide this number amongst the enterprise-rainfall combinations, the minimum optimal subsamples were obtained by multiplying minimum optimum sample size by their respective weights; and the final sampling list is shown in Table 1.

\section{Field trip to the region in May 2002}

The first phase of this study involved a field trip to the region in May 2002 with project team members travelling about $3500 \mathrm{~km}$ around the region to speak with selected individual local pastoralists and gain an understanding of the timing of key decisions and their climate information needs. A mail questionnaire based on the results of this field trip was designed and pre-tested with a selection of pastoralists visited and colleagues in collaborating organisations. The final version of the questionnaire was mailed to 88 randomly selected pastoralists in July 2002 to fulfil the minimum requirement of 55 . More questionnaires than the required minimum number were sent to help increase the likelihood of achieving the minimum target and enhance the timeliness of responses. A total of 51 responses were received from the first sampling of 88 . However, not all minimum numbers required were achieved in each of the 9 sampling categories.

In order to increase our chance of fulfilling all 9 categories, a second sample of 56 randomly selected pastoralists from the remaining population were sent questionnaires in November 2002 and from this second sample, a total of 16 responses were received. A total of 67 valid responses were received and each of the minimum number required in the 9 sampling categories was either met or exceeded (Table 1). There may, however, be a possible unmeasurable bias in the results attributable to pastoralists who did not respond to the survey.

\section{Questionnaire and statistical testing}

The questionnaire contained 6 sections namely, (i) general enterprise characteristics and respondent profile; (ii) management activities and the timing of key decisions; (iii) rainfall amounts and climate forecasts likely to influence decisions; (iv) sources of weather and climate information; (v) levels of understanding of climate phenomena used in climate information; (vi) how pastoralists would prefer to access climate information and their current levels of technology adoption.

Analyses were performed by summarising the data into contingency tables and analysing using the chi-square test, or using analysis of variance. Chi-square tests were used for count data to test whether the frequencies for one factor were independent of a second. Analysis of variance was used for ordinal rating scales with a large number of categories and for continuous measures. The assumptions of the analysis of variance were checked, and if terms were significant, then the least significant difference (1.s.d.) procedure was used for pair-wise comparisons. All statistical testing was done at a 5\% significance level.

\section{Results and discussion}

Sixty-seven valid responses from 144 randomly selected pastoralists ( 18 cattle only, 25 mixed enterprise and 24 sheep only producers) were received fulfilling or exceeding the minimum optimum sample number required in each of the 9 sampling categories (Table 1). A summary of key results follow presented as percent of the sample of 67 leases. Full details of results of this mail survey and an electronic copy of the questionnaire used in the study may be found in Keogh et al. $(2003 a, 2003 b)$.

In our mail questionnaire we employed 2 approaches to explore pastoralists' ability to interpret climate forecasts and terms commonly associated with climate information. These were 'test questions' and 'self-ratings' of pastoralist levels of knowledge and understanding.

Results highlighted 2 key issues (i) despite differences in respondent areas and enterprises types, we found seasonal climate forecasting information needs surprisingly similar across the enterprise categories, in particular the lead times preferred for January-March and May-July forecasts; and (ii) only $20 \%$ of respondents were able to correctly interpret the standard wording of a probabilistic median rainfall forecast.

Finding (ii) above raises questions about the need to simplify the language used in probabilistic forecasts and to support this with education and training opportunities that help producers interpret scientific data and jargon. It also highlights whether inappropriate decisions might be being made due to misunderstanding the forecast?

\section{Respondent profile}

We found the average number of years respondents had managed pastoral areas in the region was 19 years (ranged from 2 to 65 years) and more than half the enterprises derived income from goats. For $15 \%$ of respondent enterprises (mainly sheep only and mixed enterprises) goats made a major contribution.

During the last 10 years more than a third of respondents have increased their stock numbers, citing reasons for this increase as including enterprise changes from sheep to cattle, recent good seasons, greater access to more water or watering points, recovery after drought conditions, reduced numbers of feral goats, better herd management practices or pasture programs, and introduction of the botulism vaccine.

\section{Area managed by respondents}

Total land available in the region for pastoral lease was around 39.2 million ha with an average lease area of 163341 ha and a coefficient of variation of $58 \%$. Respondents manage approximately $33 \%$ of this area, with an average lease holding of 191689 ha (co-efficient of variation $61 \%$ ). Respondent enterprises ranged in size from about 30000 ha to over 500000 ha. Cattle tended to dominate leases in the warm season-dominated rainfall area; mixed enterprises where rainfall was distributed between warm and cool seasons and there was an even spread between sheep and mixed enterprises in cool season dominated. The average lease area where warm season dominated was about $45 \%$ 
larger than the sample average lease area and the average cattle property size was about $50 \%$ larger.

Rainfall categories. In terms of rainfall categories, $44 \%$ of the sample are in warm season dominated; $25 \%$ in cool season dominated and 31\% in cool-warm season dominated, with average areas of 283933 ha; 161970 ha and 145373 ha, respectively.

A significant difference was found in the variation of the average lease area between warm season dominated and cool season dominated $(P<0.002)$ and between warm season dominated and the cool/warm season dominated $(P<0.005)$. The average lease area in cool season dominated and cool/warm season dominated were not significantly different.

Enterprise categories. The average lease area for cattle only producers was 291866 ha, sheep 117294 ha and mixed enterprise 190980 ha with high coefficients of variation in each case.

\section{How pastoralists decide warm season stocking rates}

An important decision for the pastoralist operation in this region is the number of stock to carry during the warm season. We found $90 \%$ of respondents make this decision based on an assessment of the quantity of standing pasture and its condition (Fig. 2). This highlights an opportunity for development of a range of decision aids that could further enhance pastoralist assessments. These could range from development of technical assessment equipment for use in the field by pastoralists to providing assistance to pastoralists in the preparation of feed budgets or distribution of pasture growth or seasonal climate forecasts.

\section{When do GMS pastoralists make key decisions and undertake key management activities?}

Respondents were asked which month or months they make key decisions or undertake key management activities and if this timing can vary from year-to-year (they were able to select more than 1 month for each activity). Results are summarised in Figures 3 and 4, which also depict simplistic representations of the general austral warm season and cool season forecast periods preferred by respondents and general rainfall patterns in the region. We found for January-March

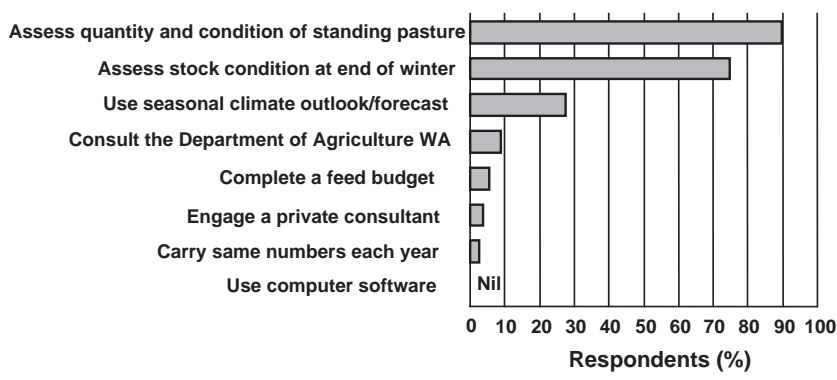

Figure 2. Tools and approaches used by pastoralists to help decide warm season stocking rates (respondents could select more than 1 response). and May-July rainfall forecasts respondents preferred lead times of around 4 months, so that forecasts would coincide with the timing of key decisions and management activities.

Cattle management and forecast lead times. Activities routinely completed during or before the preferred cool season forecast period of May-July include selling, weaning, and buying and occur on most properties from 0 to 3 months before this forecast period. Forecasts for May-July rainfall with lead times of 0 to 3 months are, therefore, likely to be useful to cattle producers because these lead times coincide with the timing of cool season management operations.

Similarly, selling, weaning and buying decisions are being made by producers 6 months before the preferred warm season forecast period of January-March and therefore, warm season rainfall forecasts issued with lead times from 0 to 6 months are likely to coincide with routine warm season management operations on cattle enterprises in the GMS region.

Sheep management and forecast lead times. The main sheep management activities occur in January before the preferred May-July forecast period and, as such, forecasts would need to be issued with lead times of not less than 4 months. Decisions such as agisting, selling, joining, shearing, lamb marking and mulesing are routinely undertaken before the warm season forecast period, January-March. For these forecasts to be useful and allow producers sufficient time to alter any decisions based on these forecasts, lead times ranging from 0 to 5 months are needed.

Goat sales. In this study goat activity was considered secondary to sheep or cattle. Goat sales were generally found to occur during January-March and August-December, with January a popular month for both considering the decision and selling. Few cattle only enterprises sold goats.

\section{How much rainfall might influence a management decision?}

We found, on average, forecasts of at least $20-50 \mathrm{~mm}$ break-of-season or follow-up rain were likely to change a management decision in any season (warm, cool, or the dry period). No significant difference was found between the least amounts of follow-up cool season rainfall across the 3 rainfall groups; nor any difference between the least amounts of follow-up warm season rainfall across the 3 rainfall groups.

Average minimum amounts were (i) $29 \mathrm{~mm}$ for break-ofseason or follow-up rain in May-July; (ii) $49 \mathrm{~mm}$ for breakof-season rain in January-March and $43 \mathrm{~mm}$ for follow-up rain in January-March and (iii) $37 \mathrm{~mm}$ in the dry period during September-December. The minimum amount for the $\mathrm{cool} /$ warm season was significantly lower than the other 2 rainfall groups.

Dry period forecasts. About one-third of the total sample considered September-December the 'dry period'. 
Some respondents said that rain at this time of the year could be a nuisance and cause major blowfly problems and flystrike. Only $9 \%$ of respondents indicated a dry period forecast would be unlikely to change a management decision

Respondents indicated that, on average, a dry period forecast of $37 \mathrm{~mm}$ would be the least amount of rain that would change a management decision; and that decisions that may be influenced by such a forecast would include decisions relating to stock sales and purchase; timing and number to muster; timing of trapping and shearing; stocking and agistment rates; paddocks to be spelled; stock numbers to carry in the warm or dry periods; purchasing chemicals to kill kite leaf; and mating, culling and weaning.

How pastoralists rated 10 climate forecasts as to their usefulness

During the field trip to the region, 10 climate forecast types were distilled from those mentioned by pastoralists as considered useful and these were included in the mail survey. Survey respondents rated the usefulness of these 10 forecasts for their business decision-making. Analysis of responses showed pastoralists preferred, in order of preference, rainfall forecasts for the next 12 months rainfall; cool season rainfall (May-July and April-August); rainfall for the next 2-20 years; and warm season rainfall (January-March) (Fig. 5). The next 12 months rainfall, May-July and April-August rainfall forecasts were rated the most useful and significantly more useful than the number of cyclones and rainfall in June.

Forecast predicting long-term average daily maximum temperatures. One of the 10 forecasts rated was a forecast that predicts the chance that the long-term average daily maximum temperatures will exceed $3-5^{\circ} \mathrm{C}$ in January-April (Fig. 5). Although this forecast was rated the least useful of the 10, it is possible that this type of forecast may increase in popularity if temperatures in the region rise as suggested by Whetton (2001). These type of temperature events, even for short periods of a few days, were reported as being able to kill young stock.

\section{Usefulness of a specific forecast}

One specific forecast was tested as to its usefulness. Respondents were asked if a forecast issued on 1 April said "There is a $70 \%$ chance of receiving $35 \mathrm{~mm}$ over 3 days in May" would influence them to change any decisions. Almost $60 \%$ of the sample said they would be likely to change their decisions if given this forecast. This $60 \%$ comprised $70 \%$ mixed producers, $56 \%$ cattle only and $50 \%$ sheep only producers.

\section{Forecast lead times preferred by pastoralists}

Respondents preferred January-March and May-July forecasts issued about 4 months before the forecast period, to allow them sufficient time to adjust any major decisions or scheduling of management activities; and for the September-December period forecasts 1 month earlier in

\section{Decision}

\begin{tabular}{|c|c|c|c|c|c|c|c|c|c|c|c|c|}
\hline \multirow{2}{*}{\multicolumn{13}{|c|}{ Buy }} \\
\hline & & & & & & & & & & & & \\
\hline Wean & & & & & & & & & & & & \\
\hline Sell - First round & & & & & & & & & & & & \\
\hline Sell-Second round & & & & & & & & & & & & \\
\hline
\end{tabular}

\section{Preferred rainfall forecast period}

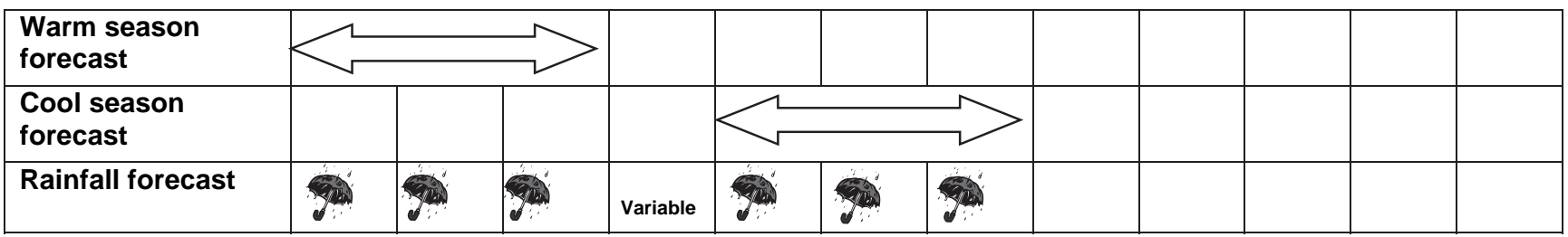

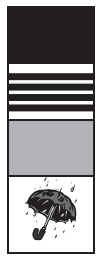

Main period for management activity

Main period for considering decision prior to making decision (sell only)

Other common months for implementing management

Main rainfall periods (Bureau of Meteorology 1998)

Figure 3. Timing of main decisions and preferred rainfall forecast periods for cattle producers in the Gascoyne-Murchison region. Cyclones occur between February and March. Rainfall is low between August and December. 
August. No significant difference was found in preferences across the 3 rainfall groups as to which months respondents preferred January-March and May-July forecasts issued.

Percentage probability forecasts likely to influence decisions

We found forecasts with a probability of occurrence of more than $60 \%$ would influence respondent management decisions. The minimum probability of exceeding median rainfall forecast was $65 \%$ for a January-March forecast; $67 \%$ for a May-July and $69 \%$ for a September-December forecast ( $n$ ranges from $45-51$ ). These are similar findings to mail respondents to a survey of western Queensland pastoralists in 2000 which found they would need, on average, a $68 \%$ probability of exceeding median rainfall forecast before they might consider changing a management decision $(n=13)$ (Keogh et al. 2004a).

In the United States and Australia it has been found that an accuracy of between 70 and $80 \%$ is desired for a seasonal forecast (Jochec et al. 2001; Pulwarty et al. 1997) before decision makers consider changing a stocking rate or crop type decision (Childs et al. 1991).
Pastoralist sources of weather and climate information and its application to decision-making

Sixty-one percent of respondents access and use weather or climate forecasts or outlook information sourced from a range of media (Fig. 6), ranging from sourcing information on general changes in weather patterns (Southern Oscillation Index and El Niño) to rural press and radio information, cool season outlooks; Hayden Walker outlook, 4 day forecasts, dry period and cyclone warnings and past rainfall.

Eighteen percent of respondents explained how they used climate and weather forecasts and information in property decision-making and how this information influenced decisions relating to setting stocking rates, mating, livestock sales, timing of tasks such as cut-off dates for shearing and fencing, mustering, stock placement on the property, developing more country, and budgeting. Almost threequarters of respondents said they would find climate forecasts, information and computer packages useful in their property decisions.

How pastoralists consider this information could be improved? We asked respondents how they consider current information they source could be improved and the following suggestions were offered - (i) by mailing

Decision

\begin{tabular}{|c|c|c|c|c|c|c|c|c|c|c|c|c|}
\hline & Jan & Feb & Mar & Apr & May & Jun & Jul & Aug & Sep & Oct & Nov & Dec \\
\hline \multicolumn{13}{|l|}{ Jet } \\
\hline \multicolumn{13}{|c|}{ Mules } \\
\hline \multicolumn{13}{|c|}{ Lamb mark } \\
\hline \multicolumn{13}{|c|}{ Shear } \\
\hline \multicolumn{13}{|l|}{ Buy } \\
\hline \multicolumn{13}{|l|}{ Agist } \\
\hline \multicolumn{13}{|l|}{ Join } \\
\hline Sell & & & & & & & & & & & & \\
\hline
\end{tabular}

\section{Preferred rainfall forecast period}

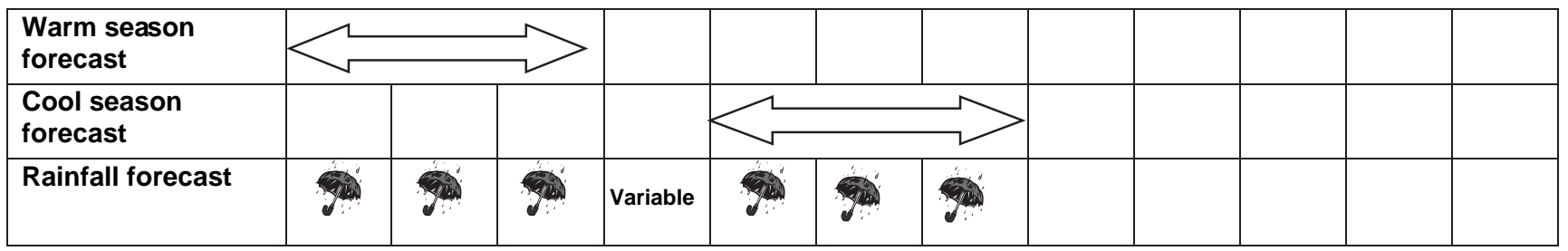

Main period for management activity

Main period for considering decision prior to making decision (sell only)

Other common months for implementing management

Main rainfall periods (Bureau of Meteorology 1998)

Figure 4. Timing of main decisions and preferred rainfall forecast periods for sheep producers in the Gascoyne-Murchison region. Note that tactical jetting occurs in other months when necessary. Cyclones occur between February and March. Rainfall is low between August and December. 
information direct to stations; (ii) more clearly defining geographic areas and producing forecasts to match; (iii) achieving greater precision in information and improving accuracy; (iv) providing easy and simple explanations of the forecasts; (v) reducing the number of information products, such as maps, presented for interpretation; (vi) issuing a $75 \%$ accurate 12 month forecast. These suggestions highlighted some important potential areas for improving forecasts and their dissemination.

\section{Do pastoralists understand the technical language used in} climate forecasts?

Test questions and 'self-ratings' of pastoralist levels of knowledge and understanding of climate forecasts and technical terms often used in these forecasts revealed (i) only $20 \%$ of respondents were able to interpret the standard wording of a probabilistic median rainfall forecast; (ii) $51 \%$ rated themselves confident they understood the term 'median rainfall' but in separate test questions only 43 and $44 \%$, respectively, of respondents correctly selected the 'mean' and 'median' value from a set of 5 numbers; (iii) only about a third of respondents were confident they understood technical terms such as El Niño, La Niña, sea surface temperatures and seasonal climate forecasting and could apply a climate forecast or information to adjust their stocking rate.

These findings suggest that pastoralists in the region could benefit from training opportunities to help them understand climate drivers and climate terminology and how forecasts can be applied in practice to decision-making.

Test questions on climate terms and climate information. Five test questions were used to assess pastoralists' general knowledge about, and ability to interpret, climate forecasts and information. These questions tested their ability to interpret a probabilistic climate forecast predicting above median rainfall; and their general levels of understanding of

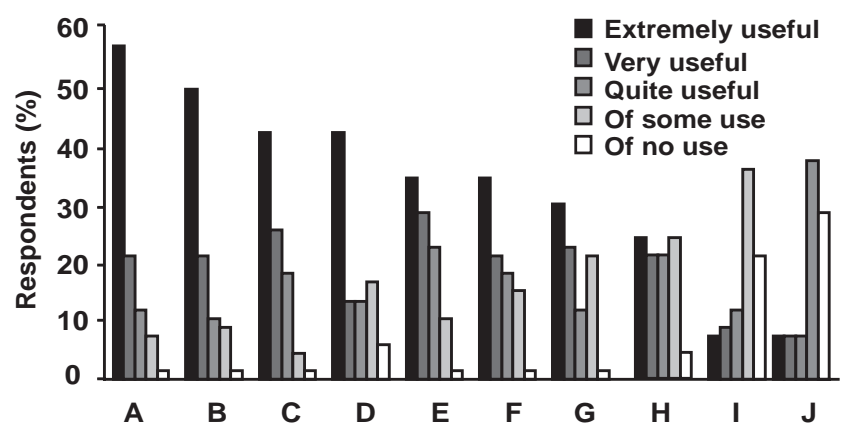

Figure 5. Distribution of attitudes to 10 climate forecasts for business decision-making. Climate forecasts surveyed were: A, rainfall next 12 months; B, rainfall May-July; C, rainfall Apr--Aug.; D, rainfall 2-20 years; E, rainfall Jan.-Mar.; F, rainfall in May; G, rainfall in June; $\mathrm{H}$, number of cyclones in summer; I, rainfall Sept.-Dec.; J, daily temperatures $>3-5^{\circ} \mathrm{C}$ above average. terms commonly used in climate forecasts such as 'mean', 'median' and the climate phenomena northwest cloudbands and the SOI. A sixth test question in the questionnaire (Keogh et al. 2003a, 2003b) related to circulation patterns of cyclones in the Southern Hemisphere, however because the choice of answers we presented to respondents could be subject to differences in opinion in terms of interpretation, we chose not to consider the results of this question in our study.

Only 20\% correctly interpreted the wording of a standard probabilistic median rainfall forecast. As mentioned previously, in a test only $20 \%$ of respondents demonstrated they understood the technical meaning of a forecast that said, 'When a climate forecaster says there is a $70 \%$ probability of receiving above median rainfall'. Only $20 \%$ selected the correct response: ' $70 \%$ of the time when this forecast is presented rainfall will be above the median'; $54 \%$ selected the response, 'The forecaster is $70 \%$ convinced that rainfall will be above the median'; $10 \%$ selected, 'Rainfall is expected to be above the median by $70 \%$ '; $10 \%$ selected, 'There will be above median rainfall'; and $6 \%$ selected 'Don't know'.

Test questions on northwest cloudbands and the SOI. Fifty-two percent correctly answered that northwest cloudbands are usually most prominent during April to August. Fifty-one percent correctly answered the question that the SOI is likely to be negative in an El Niño year compared to $68 \%$ of pastoralists surveyed in western Queensland in $2000(n=41)$ and $91 \%$ of irrigators in the northern Murray-Darling Basin surveyed in $1999(n=127)$ (Keogh et al. 2004a, 2004b). It was found that across the 3 surveys the difference between correct and incorrect responses to this question was highly significant $(P<0.001)$.

Self-rated understanding of climate technical terms. Pastoralists rated their levels of knowledge or understanding

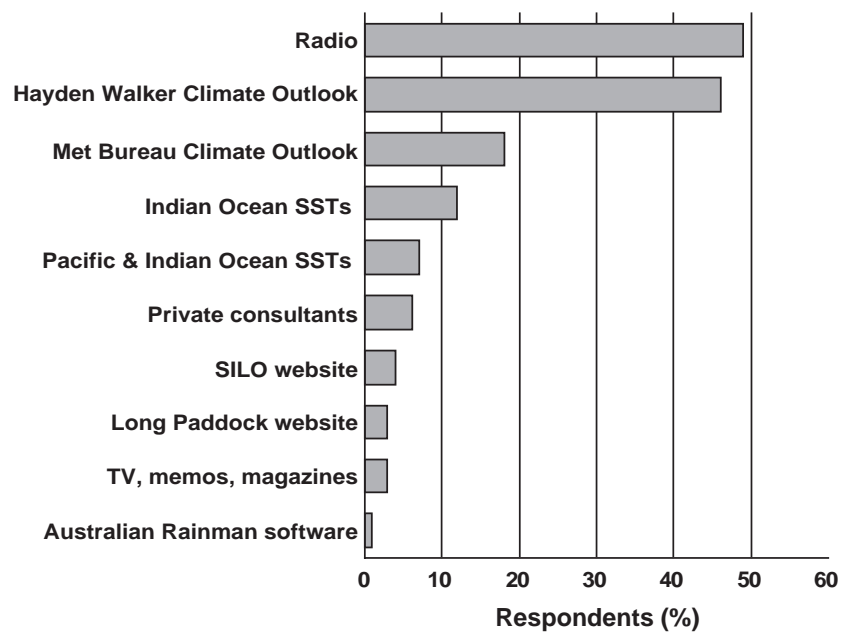

Figure 6. Sources from which pastoralists obtain climate information (respondents could select more than 1 response). 
of 9 climate terms and information using a rating scale of 1 to 10 (Keogh et al. 2003a, 2003b). However, it is noted that self-ratings are subjective perceptions and may be subject to 'optimism bias', as people can tend to hold overly favourable views of their abilities in many intellectual domains (Kruger and Dunning 1999).

Results of self-ratings by pastoralists in a survey of western Queensland in 2000 (Keogh et al. 2004a) were compared with those of GMS respondents. A chi-square test revealed significantly higher ratings for western Queensland than Gascoyne-Murchison for forecasting pasture growth, using sources of weather and climate information and seasonal climate forecasting $(P<0.001$ in each case).

In eastern Australia, the Southern Oscillation explains as much as $40 \%$ of that region's rainfall (Partridge 1994), which may account for the higher level of knowledge about the SOI by producers in western Queensland and irrigators in the northern Murray-Darling Basin.

In addition, the establishment in 1997 of the Queensland Centre for Climate Applications, a joint venture initiative between the Queensland Departments of Natural Resources and Mines and Primary Industries and Fisheries, may have exposed Queensland producers more substantially to seasonal climate forecasting compared to Western Australia producer groups. Western Australia groups may have a perception that there is low SOI skill in their region, which may also account for their lower levels of knowledge about SOI.

\section{Statistical tests to verify test questions versus self-rated knowledge}

To help verify the self-assessment ratings, a series of analysis of variances tests were carried out. These tests found differences between how correctly the 5 test questions were answered and self-rating scores of the 9 knowledge of climate terms or information. In each case, the average selfratings were higher when the test questions were answered correctly. Differences were found between how correctly the 5 test questions were answered and self-rating scores of knowledge of 6 of the 9 climate terms and information.

No significant difference was found between whether the cloudband question was answered correctly or those who selected the scientific interpretation of the forecast (that is, those who selected ' $70 \%$ of the time when this forecast is presented rainfall will be above the median') and the selfratings for each of the 9 climate terms and information.

In relation to the 5 questions used to test pastoralist understanding of climate terms and information, statistical tests revealed no significant difference between whether or not respondents were connected to the internet and how well they answered the 5 test questions. This suggests a lack of access to this technology may not have influenced their acquisition of general knowledge and understanding of climate terms and information and how to interpret forecasts.
What might be done to increase wise use of forecasts?

To increase wise use of climate forecasts the information gap between those who understand climate forecasting products and how to apply them to decisions and those who don't needs to be bridged (Changnon 1998). Three separate contexts exist here (i) the knowledge base contained within a climate forecast product and its specialist language (likely to be well-understood by climate science specialists); (ii) the knowledge base of the producer (the decision-maker) in terms of which decisions need to be made and when; and (iii) the judgment or application context as to whether a climate product output is relevant, timely and should be taken into account in a decision or decisions. Producers would be intimately acquainted with what decisions need to be made and whether the climate prediction or information has arrived in sufficient time to adjust their planning or decisions. Producers and climate science specialists need to 'work with one another' to blend these decision contexts, knowledge bases and variables. For example, groups of producers could be engaged to 'write' the climate forecasts themselves to ensure the wording and language used is clear and easy for them to understand. They could be invited by climate science specialists to review and critique climate products and their outputs, such as graphs and forecasts, and articulate any difficulties they may experience in interpreting these outputs and make suggestions as to how scientists' technical messages might be made clearer and easier to interpret.

A process of learning is needed in the use of seasonal forecasting information to ensure application is appropriate (Lemos et al. 2002). It is important also to gauge what users know about climatic events and information as this influences their perception about how they can use that information (Stern and Easterling 1999).

\section{How pastoralists prefer to access climate information}

We found email, faxback service, internet and the Department of Agriculture Western Australia's Pastoral Memo, radio and television were the most preferred ways to access climate information. Group meetings, workshops, conferences, field days and CD ROM computer software were the least preferred. These preferences were similar to the western Queensland pastoralists surveyed in 2000 (Keogh et al. 2004a).

\section{Technology adoption rates}

We found most GMS pastoralists had access to a computer with CD ROM, the internet and fax (88, 80 and $94 \%$, respectively) and $47 \%$ use computer packages in their operations. These adoption rates were not significantly different from those found in a survey of pastoralists in western Queensland conducted in 2000 (Keogh et al. 2004a) which found $90 \%$ of respondents had access to a computer 
with CD ROM, $75 \%$ to the internet and $70 \%$ used computer packages in property management.

The majority of GMS pastoralists rated the computer skill of the person in their household most likely to access climate information as either nil or basic (the balance rated it intermediate or advanced). This finding is relevant for the design and development of internet or computer-based information for this target audience.

\section{Other pastoralist suggestions}

At the end of the survey pastoralists provided other comments on what forecasts they would like for their area and their thoughts on rainfall drivers or approaches for predicting rainfall. Comments included not having sufficient knowledge about El Niño and the opinion that Indian Ocean phenomenon might be more relevant to their region. Others said they found forecasts were generally wrong or were sceptical that accurate forecasts could be produced; while others thought reasonably accurate forecasts would help make management easier.

\section{Conclusions}

The study identified the specific climate information needs of local pastoralists, which aided scientists in a research project to develop relevant skill testing scenarios to evaluate the accuracy and performance of 8 potential seasonal climate forecasting systems for the region and ensure these matched the information needs of local pastoralists. Results of the study also provided a representative benchmark for Australian rangelands grazing systems, against which climate forecast uptake and adoption rates can be measured; and provide a useful guide to inform planning for future extension activities.

Despite the fact that cattle enterprises in the region are large and concentrated in the area dominated by more variable austral warm season rainfall, compared to sheep and mixed enterprises located in austral cool season dominated, less variable rainfall regions, we found their climate information needs surprisingly similar. Respondents preferred forecasts for a specific forecast period (e.g. May-July, January-March) issued with lead times counting down from 4 to 0 months rather than rolling forecasts of 3 month period issued with zero lead time (e.g. the operational SOI phase system, Stone et al. 1996). The count down forecasts widen the window for decision making compared to those issued continuously at zero lead time.

Rainfall forecasts of, on average, at least $20-50 \mathrm{~mm}$ break-of-season or follow-up rain were likely to change a management decision in any season (warm, cool or the dry period) and forecasts with a probability of occurrence of more than $60 \%$ are likely to influence decisions. Forecasts rated of most value were forecasts for the next 12 months rainfall; May-July and April-August rainfall.
We identified low levels of knowledge amongst pastoralists about technical jargon commonly used in climate forecasts and low levels of confidence about applying this information to decisions. We found most pastoralists (80\%) were unable to correctly interpret the standard wording of a probability median rainfall forecast; and only about one-third were confident they understood climate phenomena such El Niño, La Niña, sea surface temperatures and seasonal climate forecasting and could apply a climate forecast or information to adjust their stocking rate. Perhaps of broader interest is the consideration as to whether inappropriate management decisions might be made due to misunderstanding the forecast. This hypothesis requires further research and definition. Consideration could also be given to engaging a range of producers to write the climate forecasts themselves in the language they use and understand, in consultation with the scientists who prepare the forecasts.

We found pastoralists in the region source information from various places and this information influences a range of management decisions relating to stocking rates, livestock sales and mating, timing of tasks such as fencing, deciding cut-off dates for shearing, mustering, stock placement on-property, property development, and budgeting. They preferred to access climate information by email, faxback service, internet and the Department of Agriculture Western Australia's Pastoral Memo, radio and television. Group meetings, workshops, conferences, field days and CD ROM computer software were the least preferred access methods.

At this time forecasts may play a lesser role in managing climate variability and risk in a grazing system than selection and management of the grazing system (for example, safe stocking rate and response to feed availability play a major role in managing for the variable climate and ultimately determining viability and self-reliance). Using existing ENSO-based systems forecasts of austral warm season rainfall in the GMS region have some skill, but forecasting austral cool season rainfall is difficult (Cobon et al. 2004; Stone et al. 2004). It may be more beneficial to place less emphasis on forecasting rainfall for the cool season and more emphasis on helping pastoralists better understand and manage for existing climate variability. Such an approach would provide opportunities for delivery of more training in the understanding of technical terms related to climate variability and provide a sound knowledge base for producers in readiness for the time when forecast systems improve. It would also allow an emphasis to be placed on the use of climate variability information for improved production and natural resource management outcomes.

Users need to receive support and access to experts to help them with interpretation; and training activities need to be an essential part of any forecast dissemination activity. 


\section{Acknowledgments}

The authors gratefully acknowledge the 13 pastoralist families we visited in the Gascoyne-Murchison region and the 67 pastoralist operations that participated in our mail survey, the Gascoyne-Murchison Strategy, Western Australian and Commonwealth Governments and Queensland Department of Primary Industries and Fisheries for their financial support, and Tahl Kestin in the USA for her assistance in identifying international climate literature.

\section{Disclaimer}

Neither the Queensland Departments of Natural Resources and Mines and Primary Industries and Fisheries nor the Department of Agriculture Western Australia necessarily endorses the statements expressed by the authors.

\section{References}

Anon. (1997) Gascoyne-Murchison Rangeland Strategy. Report to Cabinet sub-committee. Department of Agriculture, Western Australia.

Ayton P (1988) Perceptions of broadcast weather forecasts. Weather 43, 193-197.

Broad K, Pfaff ASP, Glantz MH (2002) Effective and equitable dissemination of seasonal-to-interannual climate forecasts: policy implications from the Peruvian fishery during El Niño 1997-98. Climatic Change 54, 415-438. doi:10.1023/A:1016164706290

Bureau of Meteorology (1998) Climatic survey, Gascoyne-Murchison, Western Australia, Bureau of Meteorology, West Perth, Australia.

Bureau of Meteorology (2004) Three-month and annual rainfall variability maps. Available at http://www.bom.gov.au/climate/ averages/variability.shtml (verified 18 December 2005)

Burnside DG (1994) A study of land management judgments in the rangelands of Western Australia and South Australia. $\mathrm{PhD}$ thesis, Department of Agriculture, University of Queensland, Australia.

Changnon D (1998) Design and test of a 'hands-on' applied climate course in an undergraduate meteorology program. Bulletin of the American Meteorological Society 79, 79-84.

Changnon SA (1992) Contents of climate predictions desired by agricultural decision makers. Journal of Applied Meteorology 31, 1488-1491. doi:10.1175/1520-0450(1992)031<1488:COCPDB> 2.0.CO;2

Childs IRW, Hastings PA, Auliciems A (1991) The acceptance of longrange weather forecasts: a question of perception? Australian Meteorological Magazine 39, 105-112.

Cobon DH, Bell K, White N, Stone R (2004) Gascoyne-Murchison Strategy milestone 4 report: seasonal forecasting for better natural resource management decisions in the Gascoyne-Murchison region of Western Australia. Report on the value of forecasts to pastoralists in the Gascoyne-Murchison, August. Department of Primary Industries and Fisheries, Queensland Government, Brisbane, Australia.

Coventry WL, Dalgleish LI (2000) Single-event verses frequency formats for presenting climate forecast probabilities: beyond reasoning abilities to judgment. Honours thesis, School of Psychology, University of Queensland, Australia.

Day KA, Aherns DG, Peacock A, Rickert KG, McKeon GM (2000) Climate tools for northern grassy landscapes. In 'Proceedings of the northern grassy landscapes conference, Katherine'. pp. 93-97. (TS-CRC: Darwin)

Drosdowsky W (2002) SST phases and Australian rainfall. Australian Meteorological Magazine 51, 1-12.
Drosdowsky W, Chambers LE (2001) Near global scale sea surface temperature anomalies as predictors of Australian seasonal rainfall. Journal of Climate 14, 1677-1687. doi:10.1175/1520-0442(2001) $014<1677$ :NACNGS $>2.0 . \mathrm{CO} ; 2$

Feldman MS (1989) 'Order without design: information production and policymaking.' (Stanford University Press: Palo Alto, CA)

Glantz MH (1996) 'Currents of change: El Niño's impact on climate and society.' (Cambridge University Press: Cambridge)

Hamlet AF, Lettenmaier DP (1999) Columbia river streamflow forecasting based on ENSO and PDO climate signals. Journal of Water Resources Planning and Management 125, 333-341. doi:10.1061/(ASCE)0733-9496(1999)125:6(333)

Hartmann HC, Pagano TC, Sorooshian S, Bales R (2002) Confidence builders: Evaluating seasonal climate forecasts from user perspectives. Bulletin of the American Meteorological Society 83, 683-698. doi:10.1175/1520-0477(2002)083<0683: CBESCF $>2.3$. $\mathrm{CO} ; 2$

Ingram KT, Roncoli C, Kirshen PH (2002) Opportunities and constraints for farmers of West Africa to use seasonal precipitation forecasts with Burkina Faso as a case study. Agricultural Systems 74, 331-349. doi:10.1016/S0308-521X(02)00044-6

Jeffrey SJ, Carter JO, Moodie K, Beswick AR (2001) Using spatial interpolation to construct a comprehensive archive of Australian climate data Environmental Modelling and Software 16, 309-330. doi:10.1016/S1364-8152(01)00008-1

Jochec KG, Mjelde JW, Lee AC, Conner JR (2001) Use of seasonal climate forecasts in rangeland-based livestock operations in West Texas. Journal of Applied Meteorology 40, 1629-1639. doi:10.1175/1520-0450(2001)040<1629:UOSCFI >2.0.CO;2

Keogh DU, Bell KL, Park JN, Cobon DH (2004a) Formative evaluation to benchmark and improve climate-based decision support for graziers in western Queensland. Australian Journal of Experimental Agriculture 44, 233-246. doi:10.1071/EA01204

Keogh DU, Abawi GY, Dutta SC, Crane AJ, Ritchie JW, Harris TR, Wright CG (2004b) Context evaluation: a profile of irrigator climate knowledge, needs and practices in the northern MurrayDarling Basin to aid development of climate-based decision support tools and information and dissemination of research. Australian Journal of Experimental Agriculture 44, 247-257. doi:10.1071/ EA02055

Keogh DU, Watson IW, Bell KL, Cobon DH, Dutta SC (2003a) 'Climate information needs and practices of pastoralists in Western Australia: a needs assessment in the Gascoyne-Murchison.' (Queensland Department of Natural Resources and Mines: Coorparoo, Qld)

Keogh DU, Watson IW, Bell KL, Cobon DH, Dutta SC (2003b) Climate information needs and practices of pastoralists in Western Australia: a needs assessment in the Gascoyne-Murchison. In 'Gascoyne-Murchison Strategy — a new lease on life; regional environmental management program (REMP), climate forecasting, climate information needs of pastoralists in the GM region. The results of a needs analysis done as part of the GMS seasonal forecasting project'. Available at http://www.gms.wa.gov.au/main $\%$ 20pages/related\%20documents.html1450KB (verified 18 December 2005)

Klopper E (1999) The use of seasonal forecasts in South Africa during the 1997/98 rainfall season. Water $S A$ 25, 311-316.

Kruger J, Dunning D (1999) Unskilled and unaware of it: how difficulties in recognizing one's own incompetence lead to inflated self-assessments. Journal of Personality and Social Psychology 77, 1121-1134. doi:10.1037/0022-3514.77.6.1121

Lee DM, Gaffney DO (1986) 'District rainfall deciles — Australia. Meteorological summary.' (Australian Government Publishing Service: Canberra) 
Lemos MC, Finan TJ, Fox RW, Nelson DR, Tucker J (2002) The use of seasonal climate forecasting in policymaking: lessons from Northwest Brazil. Climatic Change 55, 479-507. doi:10.1023/ A: 1020785826029

Lewis M (2001) The Gascoyne-Murchison Strategy: a pilot for the new way forward for rangelands? Range Management Newsletter 01/3, 10.

McIntosh PC, Ash A, Stafford Smith M (2002) Ocean-based forecasts may help farm profits. Farming Ahead 123, 32-34.

McIntosh PC, Ash A, Stafford Smith M (In press) From oceans to farms: using sea-surface temperatures in agricultural management. Journal of Climate.

McKeon GM, Hall W, Henry BH, Stone G, Watson IW (Eds) (2004) 'Pasture degradation and recovery in Australia's rangelands. Learning from history.' (Queensland Department of Natural Resources, Mines and Energy: Brisbane)

Murphy AH, Brown BG (1983) Forecast terminology: composition and interpretation of public weather forecasts. Bulletin of the American Meteorological Society 64, 13-22.

Nicholls N, Drosdowsky W, Lavery B (1997) Australian rainfall variability and change. Weather 52, 66-72.

Partridge IJ (Ed.) (1994) 'Will it rain? The effects of the Southern Oscillation and El Niño on Australia.' (Department of Primary Industries: Brisbane)

Pastoral Industry Economic Monitoring Requirements Pastoral Industry Working Group (2003) Pastoral Industry Economic Monitoring Requirements. Report to the Minister for Planning and Infrastructure. Department of Planning and Infrastructure, Perth, Australia.

Payne AL, Curry PJ, Spencer GF (1987) An inventory and condition survey of the Carnarvon Basin, Western Australia. Technical Bulletin No. 73. Western Australia Department of Agriculture.

Podestá GP, Letson D, Messina CD, Royce FS, Ferreyra RA, Jones JW, Hansen JW, Llovett I, Grondona MO, O'Brien JJ (2002) Use of ENSO-related climate information in agricultural decision making in Argentina: a pilot experience. Agricultural Systems 74, 371-392. doi:10.1016/S0308-521X(02)00046-X

Pringle HJR, Van Vreeswyk AME, Gilligan SA (1994) An inventory and condition survey of rangelands in the north-eastern Goldfields, Western Australia. Technical Bulletin No. 87. Western Australia Department of Agriculture.

Pulwarty RS, Redmond KT, Kelly T (1997) Climate and salmon restoration in the Columbia River Basin: the role and usability of seasonal forecasts. Bulletin of the American Meteorological Society 78, 381-397. doi:10.1175/1520-0477(1997)078<0381:CASRIT> 2.0.CO;2
Scheaffer RL, Mendenhall W, Ott L (1990) 'Elementary survey sampling.' 4th edn. (PWS-Kent Publishing Company: Boston)

Sonka ST, Changnon SA, Hofing SL (1992) How agribusiness uses climate predictions: implications for climate research and provision of predictions. Bulletin of the American Meteorological Society 73, 1999-2008. doi:10.1175/1520-0477(1992)073<1999:HAUCPI> 2.0.CO;2

Stern PC, Easterling WE (Eds) (1999) 'Making climate forecasts matter. National Research Council, panel on human dimensions of seasonal-to-interannual climate variability.' (National Academy Press: Washington DC)

Stone RC, Hammer GL, Marcussen T (1996) Prediction of global rainfall probabilities using phases of the Southern Oscillation Index. Nature 384, 252-255. doi:10.1038/384252a0

Stone R, White N, Treloar N, Bell K, Lennox S (2004) Gascoyne-Murchison Strategy milestone 3 summary report. Seasonal forecasting for better natural resource management decisions in the Gascoyne-Murchison region of Western Australia, evaluation of forecast systems for rainfall (sic) the Gascoyne-Murchison, August. Department of Primary Industries and Fisheries, Queensland Government.

Treloar NC (2002) Luni-solar tidal influences on climate variability International Journal of Climatology 22, 1527-1542. doi:10.1002/ joc. 783

Vanclay F (2004) Social principles for agricultural extension to assist in the promotion of natural resource management Australian Journal of Experimental Agriculture 44, 213-222. doi:10.1071/EA02139

Van Vreeswyk AME, Godden PT (1998) Pastoral resources and their management in the Sandstone-Yalgoo-Paynes find area, Western Australia. Agriculture Western Australia Miscellaneous Publication $1 / 98$.

Whetton P (2001) Climate change. Projects for Australia. (CSIRO Publishing: Melbourne) Available at www.dar.csiro.au/publications/ projections2001.pdf (verified 18 December 2005)

Wilcox DG, McKinnon EA (1972) A report on the condition of the Gascoyne River catchment. Western Australian Department of Agriculture Technical Bulletin No. 2.

Received 23 December 2004, accepted 15 April 2005 